\title{
Determinants of early initiation of breastfeeding in Ghana: a population-based cross-sectional study using the 2014 Demographic and Health Survey data
}

\author{
Abdul-Aziz Seidu ${ }^{1,2}$ (D) Edward Kwabena Ameyaw ${ }^{3 *}$ (D) Bright Opoku Ahinkorah ${ }^{3}$ (D) and Freda Bonsu ${ }^{4}$
}

\begin{abstract}
Background: The World Health Organisation (WHO) recommends that breastfeeding should be initiated within the first hour of delivery followed by exclusive breastfeeding up to 6 months. This study examined the determinants of early initiation of breastfeeding in Ghana using data from the 2014 Ghana Demographic and Health Survey.

Methods: A sample size of 4219 was used for the study. Descriptive statistics was conducted to ascertain the proportion of children who had early initiation of breastfeeding after which binary logistic regression analysis was carried out. Results were presented using frequencies, percentages, unadjusted and adjusted odds ratios. Statistical significance was pegged at $p<0.05$.

Results: Children of first birth order $[\mathrm{AOR}=0.71, \mathrm{Cl}=0.61-0.84]$, those who were delivered by non-professionals $[A O R=0.51, \mathrm{Cl}=0.30-0.88]$ and those whose mothers were Traditionalists $[A O R=0.65, \mathrm{Cl}=0.46-0.92]$ and MoleDagbanis $[A O R=0.69, \mathrm{Cl}=0.54-0.89]$ were less likely to go through early initiation of breastfeeding compared to those of 2-4 birth order, those who were delivered by health professionals, those whose mothers were Christians and Akan, respectively. Conversely, children born to mothers who read newspaper/magazine at least once a week were more likely to go through early initiation of breastfeeding, compared to those who never read newspaper/magazine $[\mathrm{AOR}=$ $1.40, \mathrm{Cl}=1.01-1.95]$. Children born to mothers who watched television less than once a week were more likely to go through early initiation of breastfeeding compared to those who watched television at least once a week $[A O R=1.40$, $\mathrm{Cl}=1.01-1.95]$. Finally, women from the Northern $[\mathrm{AOR}=2.40, \mathrm{Cl}=[1.77-3.26]$ and Upper East regions $[\mathrm{AOR}=2.57$, $\mathrm{Cl}=[1.86-3.56]$ practiced early initiation of breastfeeding compared to those from the Ashanti region.
\end{abstract}

Conclusions: Empowering healthcare providers to be consistent in early breastfeeding initiation advocacy and effective community engagement on the need to embrace and practice early initiation of breastfeeding can improve the situation.

Keywords: Early initiation, Breastfeeding, Newborn health, Ghana

\footnotetext{
* Correspondence: edward k.ameyaw@student.uts.edu.au

${ }^{3}$ School of Public Health, Faculty of Health, University of Technology Sydney, Sydney, Australia

Full list of author information is available at the end of the article
}

(c) The Author(s). 2020 Open Access This article is licensed under a Creative Commons Attribution 4.0 International License, which permits use, sharing, adaptation, distribution and reproduction in any medium or format, as long as you give appropriate credit to the original author(s) and the source, provide a link to the Creative Commons licence, and indicate if changes were made. The images or other third party material in this article are included in the article's Creative Commons licence, unless indicated otherwise in a credit line to the material. If material is not included in the article's Creative Commons licence and your intended use is not permitted by statutory regulation or exceeds the permitted use, you will need to obtain permission directly from the copyright holder. To view a copy of this licence, visit http://creativecommons.org/licenses/by/4.0/. The Creative Commons Public Domain Dedication waiver (http://creativecommons.org/publicdomain/zero/1.0/) applies to the data made available in this article, unless otherwise stated in a credit line to the data. 


\section{Background}

Breastfeeding is essential for the growth and development of newborns by providing vital nutrients [1]. The World Health Organisation (WHO) recommends that breastfeeding should be initiated within the first hour of delivery followed by exclusive breastfeeding up to 6 months [2]. Early initiation of breastfeeding is defined as the initiation of breast milk feeding within 1 hour after delivery [3]. Early initiation of breastfeeding has several health benefits such as increased ability of the immune system to resist infections, reduction in the risk of diarrhea, and increased survival rate of children [4]. According to Mugadza, Zvinavashe, Gumbo and Pedersen [5], early initiation of breastfeeding reduces neonatal mortality by $33 \%$. On the other hand, Berkat and Sutan [6] found that late initiation of breastfeeding leads to high neonatal morbidity and mortality.

This is affirmed by some recent systematic reviews and meta-analysis. For instance, Smith and colleagues reported that infants whose breastfeeding initiation occur between 2 and 23 hours after birth have 33\% increased risk of neonatal mortality compared with those whose initiation occurs in less than 1 hour [7]. Prospective analysis of pooled randomised trials from Ghana, India, and Tanzania also revealed 1.79 increased likelihood of mortality among infants whose breastfeeding initiation occurred between 2 and 23 hours compared to those initiated within the first hour [8].

Despite WHO's recommendation that every newborn should be given breast milk within 1 hour after delivery, a lot of mothers in low-and middle-income countries do not practice early initiation of breastfeeding [9-11]. In Ghana, a little over half (56\%) of children are breastfed within 1 hour of birth [12]. This situation is worrisome considering the fact that one in ten children (12\%) had diarrhoea in 2014, with a neonatal mortality rate of 29 deaths per 1000 live births. Additionally, infant mortality rate stood at 41 deaths per 1000 live births with under-5 mortality rate of 60 deaths per 1000 live births [12].

Several studies in low and middle-income countries, have identified mother's age, birth order, preceding birth interval, place of delivery, mode of delivery, gender of the child, wealth index, residence and region as determinants of early initiation of breastfeeding [13-15]. A study that was conducted in one of the Districts in Ghana used qualitative approach to explore why women initiate breast-feeding early or late, who gives advice about initiation and what foods or fluids are given to babies when breastfeeding initiation is late [16]. To the best of our knowledge, it appears there is no study in Ghana that has looked at the determinants of early initiation of breastfeeding using nationally representative data. This study, therefore, examined the determinants of early initiation of breastfeeding in Ghana using data from the 2014 Ghana Demographic and Health Survey (GDHS). Findings from the study will be useful to policymakers, health care providers, and stakeholders in improving the practice of early initiation of breastfeeding in the country.

\section{Methods \\ Description of the survey and sampling}

We used data from the child recode file of the 2014 version of the Ghana Demographic and Health Survey (GDHS). The GDHS is a nationwide survey which covers all the erstwhile ten regions and is conducted every 5 years [12]. The survey is conducted by the Ghana Statistical Service and the Ghana Health Service with Inner City Fund(ICF) International giving technical support through the MEASURE DHS Program. The survey adopts a two-stage sampling design. The first stage involves the selection of clusters consisting of enumeration areas delineated for the Population and Housing Census preceding the survey [12]. The second stage involved the selection of households from each cluster. A total of 9396 women (97.3\% response rate) were interviewed for the survey. The survey provides a complete birth history of women and their children. Further details of the methodology can be found in the final report [12]. Actual sample of mothers with children having complete cases on the variables used in this study were 4219 children. Permission to use the dataset was obtained from MEASURE DHS. Dataset is available to the public at www.measuredhs.org. We relied on the "Strengthening the Reporting of Observational Studies in Epidemiology" (STROBE) statement in writing the manuscript.

\section{Definition of variables}

The outcome variable was derived from the question "How long after birth did you first put (NAME) to the breast?" Responses were recorded in number of hours or days [14]. Our outcome variable "early initiation breastfeeding" was defined as initiation of breastfeeding within 1 hour of birth and was expressed as a dichotomous variable with category 1 for initiation of breastfeeding within 1 hour (early) and category 0 for initiation of breastfeeding after 1 hour (late). The independent variables were chosen based on previous studies and availability in the dataset $[1,13]$. Some of the variables were recoded while others were adopted as reported in the 2014 GDHS. These included sex of child, size at birth, birth order, twin status, type of delivery assistance, place child was delivered (child factors). Others were mother's age, marital status, religion, ethnicity, educational level, working status, frequency of listening to radio, frequency of listening to radio, frequency of watching television, number of ANC visits (maternal factors) and region, 
Table 1 Distribution of early initiation of breastfeeding across the child, maternal and community/household level characteristics of women

\begin{tabular}{|c|c|c|}
\hline \multirow[t]{2}{*}{ Variable } & \multicolumn{2}{|c|}{ Initiation of breastfeeding $(n=4219)$} \\
\hline & $\begin{array}{l}\text { After } 1 \text { hour } \\
\text { n (\%) } \\
1869(44.3 \%)\end{array}$ & $\begin{array}{l}\text { Within } 1 \mathrm{hc} \\
\mathrm{n}(\%) \\
2350\left(55.7^{\circ}\right.\end{array}$ \\
\hline \multicolumn{3}{|l|}{ Child characteristics } \\
\hline \multicolumn{3}{|l|}{ Sex of child } \\
\hline Male & $1019(54.1)$ & $1201(51.5)$ \\
\hline Female & $866(45.9)$ & $1132(48.5)$ \\
\hline \multicolumn{3}{|l|}{ Size at birth } \\
\hline Larger than Average & $953(50.5)$ & $1203(51.6)$ \\
\hline Average & $602(31.9)$ & $783(33.6)$ \\
\hline Smaller than average & $331(17.6)$ & $347(14.9)$ \\
\hline \multicolumn{3}{|l|}{ Birth order } \\
\hline 1 & $477(25.2)$ & $480(20.6)$ \\
\hline $2-4$ & $932(49.4)$ & $1267(54.3)$ \\
\hline $5+$ & $476(25.2)$ & $586(25.1)$ \\
\hline \multicolumn{3}{|l|}{ Twin status } \\
\hline Single birth & $1842(97.7)$ & $2271(97.3)$ \\
\hline Twin & $44(2.3)$ & $62(2.7)$ \\
\hline \multicolumn{3}{|c|}{ Type of assistance during delivery } \\
\hline Non-health professional & $503(26.7)$ & $517(22.2)$ \\
\hline Health professional & $1383(73.3)$ & $1816(77.8)$ \\
\hline \multicolumn{3}{|l|}{ Place child was delivered } \\
\hline Home & $502(26.6)$ & $536(23.0)$ \\
\hline Health facility & $1384(73.4)$ & $1797(77.0)$ \\
\hline \multicolumn{3}{|l|}{ Maternal factors } \\
\hline \multicolumn{3}{|l|}{ Age } \\
\hline $15-24$ & 393 (20.9) & $512(22.0)$ \\
\hline $25-34$ & $872(46.2)$ & $1143(49.0)$ \\
\hline $35-49$ & $621(32.9)$ & $678(29.1)$ \\
\hline \multicolumn{3}{|l|}{ Marital status } \\
\hline Not Married & 751 (39.8) & 871 (37.3) \\
\hline Married & $1134(60.2)$ & $1463(62.7)$ \\
\hline \multicolumn{3}{|l|}{ Religion } \\
\hline Christianity & $1450(76.9)$ & $1774(76.0)$ \\
\hline Islam & $292(15.5)$ & $415(18.0)$ \\
\hline Traditionalist & $66(3.5)$ & $60(2.6)$ \\
\hline No region & $78(4.1)$ & $85(3.6)$ \\
\hline \multicolumn{3}{|l|}{ Ethnicity } \\
\hline Akan & $860(45.6)$ & $1138(48.8)$ \\
\hline Ga-Dangbme & $142(7.6)$ & $126(5.4)$ \\
\hline Ewe & $279(14.8)$ & $282(12.1)$ \\
\hline Mole-Dagbani & 305 (16.2) & $426(18.3)$ \\
\hline Others & 299 (15.9) & 362 (15.5) \\
\hline
\end{tabular}

\section{Education}


Table 1 Distribution of early initiation of breastfeeding across the child, maternal and community/household level characteristics of women (Continued)

\begin{tabular}{|c|c|c|}
\hline \multirow[t]{2}{*}{ Variable } & \multicolumn{2}{|c|}{ Initiation of breastfeeding $(n=4219)$} \\
\hline & $\begin{array}{l}\text { After } 1 \text { hour } \\
\text { n (\%) } \\
1869(44.3 \%)\end{array}$ & $\begin{array}{l}\text { Within } 1 \text { hour } \\
\text { n (\%) } \\
2350(55.7 \%)\end{array}$ \\
\hline No education & $426(24.5)$ & $644(27.6)$ \\
\hline Primary & $406(21.5)$ & $422(18.1)$ \\
\hline Secondary & $937(49.7)$ & $1151(49.2)$ \\
\hline Higher & $80(4.2)$ & $116(5.0)$ \\
\hline \multicolumn{3}{|l|}{ Working status } \\
\hline Not working & $329(17.5)$ & 409 (17.5) \\
\hline Working & $1.556(82.5)$ & $1925(82.5)$ \\
\hline \multicolumn{3}{|c|}{ Frequency of reading newspaper/magazine } \\
\hline Not at all & $1655(87.8)$ & $2045(87.7)$ \\
\hline Less than once a week & $150(7.9)$ & $145(6.2)$ \\
\hline At least once a week & $81(4.3)$ & $143(6.1)$ \\
\hline \multicolumn{3}{|c|}{ Frequency of listening to radio } \\
\hline Not at all & $333(17.7)$ & $403(17.3)$ \\
\hline Less than once a week & $600(31.8)$ & $780(33.4)$ \\
\hline At least once a week & $952(50.5)$ & $1150(49.3)$ \\
\hline \multicolumn{3}{|c|}{ Frequency of watching television } \\
\hline Not at all & $538(28.5)$ & $667(28.6)$ \\
\hline Less than once a week & $445(23.6)$ & $635(27.2)$ \\
\hline At least once a week & $903(47.9)$ & $1032(44.2)$ \\
\hline \multicolumn{3}{|l|}{ Number of ANC visits } \\
\hline 0 & $58(3.1)$ & $51(2.2)$ \\
\hline $1-3$ & $215(11.4)$ & $198(8.5)$ \\
\hline $4+$ & $1613(85.5)$ & $2085(89.4)$ \\
\hline \multicolumn{3}{|c|}{ Community/household factors } \\
\hline \multicolumn{3}{|l|}{ Region } \\
\hline Western & $176(9.3)$ & $260(11.1)$ \\
\hline Central & $184(9.8)$ & $282(12.1)$ \\
\hline Greater Accra & $330(17.5)$ & $353(15.1)$ \\
\hline Volta & $172(9.1)$ & $151(6.5)$ \\
\hline Eastern & $191(10.1)$ & $207(8.9)$ \\
\hline Ashanti & $385(20.4)$ & $359(15.4)$ \\
\hline Brong-Ahafo & $142(7.5)$ & $235(10.1)$ \\
\hline Northern & $181(9.6)$ & $314(13.4)$ \\
\hline Upper east & $58(3.1)$ & $124(5.3)$ \\
\hline Upper west & $65(3.4)$ & $48(2.1)$ \\
\hline \multicolumn{3}{|l|}{ Place of residence } \\
\hline Rural & $1008(53.5)$ & $1269(54.4)$ \\
\hline Urban & $878(46.5)$ & $1063(45.6)$ \\
\hline \multicolumn{3}{|l|}{ Wealth index } \\
\hline Poor & 765 (40.6) & $984(42.2)$ \\
\hline Middle & $403(21.4)$ & $442(18.9)$ \\
\hline
\end{tabular}


Table 1 Distribution of early initiation of breastfeeding across the child, maternal and community/household level characteristics of women (Continued)

\begin{tabular}{|c|c|c|}
\hline \multirow[t]{3}{*}{ Variable } & \multicolumn{2}{|c|}{ Initiation of breastfeeding $(n=4219)$} \\
\hline & $\begin{array}{l}\text { After } 1 \text { hour } \\
\text { n (\%) }\end{array}$ & $\begin{array}{l}\text { Within } 1 \text { hour } \\
\text { n (\%) }\end{array}$ \\
\hline & $1869(44.3 \%)$ & $2350(55.7 \%)$ \\
\hline Rich & $717(38.0)$ & $907(38.9)$ \\
\hline
\end{tabular}

Source: 2014 Ghana Demographic and Health Survey

place of residence and wealth index (community/household factors) (see Table 1).

\section{Statistical analysis}

Analysis was done using Stata version 14. The first step of the analysis involved the distribution of early initiation of breastfeeding across the child, maternal and community/household level characteristics of women using frequency and percentages (see Table 1). This was followed by a bivariate analysis using logistic regression to assess the association between early initiation of breastfeeding and the child, maternal and community/ household factors. This was presented in three models, with the child factors in model I, maternal factors in Model II and community/household factors in Model III. The results were presented as unadjusted odds ratios (UORs) at $p<0.05$ (see Table 2). Variables that were significant at the bivariate level (5\% margin), were used to build three models in a multivariable logistic regression analysis. Model I was made up of the child factors and early initiation of breastfeeding only. In Model II, the maternal factors only were added to the variables in Model I. Finally, Model III was a complete model that had the child, maternal and community/household factors and early initiation of breastfeeding. The results were presented as adjusted odds ratios (AORs) at $\mathrm{p}<0.05$ (see Table 3). Sample weight (v005/1000,000) was applied to correct for over-and under-sampling while the SVY command was used to account for the complex survey design and generalizability of the findings.

\section{Ethical consideration}

The DHS Program reports that ethics approval was sought from the National Public Health Reference Laboratory of the GHS and Noguchi Memorial Institute for Medical Research all in Ghana. It was further reported that informed consent was provided by all study participants.

\section{Results}

Distribution of early initiation of breastfeeding across the child, maternal and community/household characteristics of women

Table 1 presents results of the distribution of early initiation of breastfeeding across the child, maternal and community/household characteristics of women. We found that $55.7 \%$ of women initiated breastfeeding within the first hour of delivery. In terms of the child characteristics, most of the children who went through early initiation of breastfeeding were males (51.5\%), larger than average size at birth (51.6\%), 2-4 birth order (54.3\%), were born single (97.3\%), were delivered with the help of health professionals $(77.8 \%)$, and at the health facility $(77.0 \%)$. With the maternal factors, most of the women who practiced early initiation of breastfeeding were aged 25-34 (49.0\%), married (62.7\%), Christians (76.0\%), Akans (48.8\%), had secondary education (49.2\%), never read newspaper (87.7\%), listened to radio at least once a week (49.3\%), watched television at least once a week (44.2), and had 4+ ANC visits. With community/household factors, women from the Ashanti region (15.4\%), those in rural areas (54.4\%) and those of poor wealth index had the highest prevalence of early initiation of breastfeeding.

\section{Bivariate results on the predictors of early initiation of breastfeeding in Ghana}

Table 2 shows the bivariate results of early initiation of breastfeeding in Ghana. At $p<0.05$, birth order (UOR = $\left.0.74^{* * n+} \mathrm{CI}=[0.63-0.86]\right)$, place of delivery $\left(\mathrm{UOR}=0.82^{\mathrm{min}}\right.$ $\mathrm{CI}=[0.72-0.94])$ and type of assistance during delivery $\left(\mathrm{UOR}=0.79^{\text {*wa }} \mathrm{CI}=[0.69-0.91]\right)$ were the child factors that showed statistically significant relationship with early initiation of breastfeeding in Ghana. With maternal factors, religion ( $\left.\mathrm{UOR}=0.66^{\prime \prime} \mathrm{CI}=[0.48-0.91]\right)$, ethnicity $\left(\mathrm{UOR}=0.69^{\prime \prime} \quad \mathrm{CI}=[0.51-0.93]\right)$, frequency of reading newspaper $\left(\mathrm{UOR}=1.39^{\prime \prime} \mathrm{CI}=[1.02-1.90]\right)$ and frequency of watching television $\left(\mathrm{UOR}=1.26^{* * *} \mathrm{CI}=[1.08-1.49]\right)$ showed statistically significant associations with early initiation of breastfeeding at $p<0.05$. Region was the only community/household variable that was significant at the bivariate level.

\section{Multivariable results}

As shown in Table 3, children of first birth order $[\mathrm{AOR}=0.71, \mathrm{CI}=0.61-0.84]$, those who were delivered by non-professionals $[\mathrm{AOR}=0.51, \mathrm{CI}=0.30-0.88]$ and those whose mothers were Traditionalists $[\mathrm{AOR}=0.65$, $\mathrm{CI}=0.46-0.92]$ and Mole-Dagbanis $[\mathrm{AOR}=0.69, \mathrm{CI}=$ 0.54-0.89] were less likely to go through early initiation 
Table 2 Unadjusted Odds Ratio for early initiation of breastfeeding in Ghana ( $n=4219)$

\begin{tabular}{ll}
\hline Variables & $\begin{array}{l}\text { Model I } \\
\text { UOR }(\mathbf{9 5} \% \mathrm{Cl})\end{array}$ \\
\hline $\begin{array}{l}\text { Child factors } \\
\text { Sex of child }\end{array}$ & \\
$\quad$ Male & Ref \\
Female & $1.07[0.94-1.21]$ \\
Size at birth & \\
Larger than Average & Ref \\
Average & $0.98[0.85-1.12]$ \\
Smaller than average & $0.89[0.75-1.05]$ \\
Birth order & \\
1 & $0.74^{* * *}[0.63-0.86]$ \\
$2-4$ & Ref \\
$5+$ & $0.89[0.77-1.51]$
\end{tabular}

\section{Twin status}

$\begin{array}{ll}\text { Single birth } & \text { Ref } \\ \text { Twin } & 1.03 \text { [0.69-1.52] }\end{array}$

\section{Type of assistance during delivery}

$\begin{array}{ll}\text { Non-health professional } & 0.79^{* * *}[0.69-0.91] \\ \text { Health professional } & \text { Ref } \\ \text { Place child was delivered } & \\ \text { Home } & 0.82^{* *}[0.72-0.94] \\ \text { Health facility } & \text { Ref }\end{array}$

Maternal factors

Age

15-24

25-34

35-49

0.97 [0.83-1.14]

0.91 [0.79-1.05]

Marital status

Not Married

Married

0.98 [0.86-1.11]

Religion

Christianity

Islam

Traditionalist

No region

Ref

\section{Ethnicity}

Akan
Ga-Dangbme
Ewe
Mole-Dagbani
Others

\section{Education}

No education

Primary

Ref

Ref

1.11 [0.95-1.29]

$0.66^{*}[0.48-0.91]$

1.11 [0.81-1.52]

Ref

$0.69^{*}$ [0.51-0.93]

$0.73^{* *}[0.59-0.90]$

0.91 [0.78-1.06]

0.88 [0.75-1.05]

1.01 [0.88-1.16]

0.91 [0.78-1.07] 
Table 2 Unadjusted Odds Ratio for early initiation of breastfeeding in Ghana ( $n=4219)$ (Continued)

\begin{tabular}{|c|c|c|}
\hline Variables & $\begin{array}{l}\text { Model I } \\
\text { UOR }(95 \% \mathrm{Cl})\end{array}$ & $\begin{array}{l}\text { Model II } \\
\text { UOR }(95 \% \mathrm{Cl})\end{array}$ \\
\hline Secondary & & Ref \\
\hline Higher & & $1.02[0.74-1.41]$ \\
\hline \multicolumn{3}{|l|}{ Working status } \\
\hline Not working & & $1.04[0.89-1.22]$ \\
\hline Working & & Ref \\
\hline \multicolumn{3}{|l|}{ Media exposure } \\
\hline \multicolumn{3}{|c|}{ Frequency of reading newspaper/magazine } \\
\hline Not at all & & Ref \\
\hline Less than once a week & & $0.78[0.61-1.01]$ \\
\hline At least once a week & & $1.39^{*}[1.02-1.90]$ \\
\hline \multicolumn{3}{|c|}{ Frequency of listening to radio } \\
\hline Not at all & & $0.93[0.79-1.10]$ \\
\hline Less than once a week & & $1.09[0.95-1.25]$ \\
\hline At least once a week & & Ref \\
\hline \multicolumn{3}{|l|}{ Frequency of watching TV } \\
\hline Not at all & & $1.08[0.94-1.24]$ \\
\hline Less than once a week & & $1.26^{* *}[1.08-1.49]$ \\
\hline At least once a week & & Ref \\
\hline \multicolumn{3}{|l|}{ Number of ANC visits } \\
\hline 0 & & $0.74[0.52-1.05]$ \\
\hline $1-3$ & & $0.82[0.67-1.00]$ \\
\hline $4+$ & & Ref \\
\hline
\end{tabular}

\section{Community/household factors}

Region

Western

$1.38^{*}[1.05-1.81]$

Central

$1.58^{* *}[1.20-2.07]$

Greater Accra

1.06 [0.80-1.42]

Volta

0.82 [0.61-1.09]

Eastern

1.05 [0.80-1.39]

Ashanti

Ref

Brong-Ahafo

$1.74^{* * *}[1.33-2.28]$

Northern

Upper east

Upper west

$1.58^{* * *}[1.23-2.04]$

$1.95^{* * *}[1.48-2.58]$

0.78 [0.59-1.04]

\section{Place of residence}

Rural

Ref

Urban

Wealth index

Poor

Ref

Middle

0.90 [0.77-1.06]

Rich

1.00 [0.87-1.15]

${ }^{*} p<0.05,{ }^{* *} p<0.01,{ }^{* * * *} p<0.001$. Ref Reference category, Cl Confidence Interval

Source: 2014 Ghana Demographic and Health Survey 
Table 3 Adjusted Odds Ratio for early initiation of breastfeeding in Ghana

\begin{tabular}{|c|c|c|c|}
\hline Variable & $\begin{array}{l}\text { Model I } \\
\text { AOR }(95 \% \mathrm{Cl})\end{array}$ & $\begin{array}{l}\text { Model II } \\
\text { AOR }(95 \% \mathrm{Cl})\end{array}$ & $\begin{array}{l}\text { Model III } \\
\text { AOR }(95 \% \mathrm{Cl})\end{array}$ \\
\hline \multicolumn{4}{|l|}{ Child factors } \\
\hline \multicolumn{4}{|l|}{ Birth order } \\
\hline $1 \mathrm{st}$ & $0.718^{* * *}[0.61-0.84]$ & $0.72^{* * *}[0.62-0.85]$ & $0.71^{* * *}[0.61-0.84]$ \\
\hline $2-4$ th & Ref & Ref & Ref \\
\hline 5 and above & $0.93[0.80-1.07]$ & $0.911[0.79-1.06]$ & $0.91[0.78-1.06]$ \\
\hline \multicolumn{4}{|l|}{ Type of delivery assistance } \\
\hline Non-health professional & $0.50^{*}[0.30-0.85]$ & $0.53^{*}[0.31-0.89]$ & $0.51^{*}[0.30-0.88]$ \\
\hline Health professional & Ref & Ref & Ref \\
\hline \multicolumn{4}{|l|}{ Place of delivery } \\
\hline Health facility & $1.55[0.92-2.63]$ & $1.47[0.87-2.49]$ & $1.45[0.85-2.48]$ \\
\hline Home & Ref & Ref & Ref \\
\hline \multicolumn{4}{|l|}{ Maternal factors } \\
\hline \multicolumn{4}{|l|}{ Religion } \\
\hline Christianity & & Ref & Ref \\
\hline Islam & & $1.15[0.96-1.37]$ & $1.08[0.89-1.30]$ \\
\hline Traditionalist & & $0.72[0.51-1.02]$ & $0.65^{*}[0.46,0.92]$ \\
\hline No region & & $1.16[0.84-1.61]$ & $1.21[0.88-1.66]$ \\
\hline \multicolumn{4}{|l|}{ Ethnicity } \\
\hline Akan & & Ref & Ref \\
\hline Ga-Dangbme & & $0.71^{*}[0.52-0.95]$ & $0.83[0.60-1.15]$ \\
\hline Ewe & & $0.77^{*}[0.63-0.95]$ & $1.03[0.78-1.35]$ \\
\hline Mole-Dagbani & & $0.88[0.73-1.05]$ & $0.69^{* *}[0.54-0.89]$ \\
\hline Others & & $0.92[0.76-1.11]$ & $0.71^{* *}[0.56-0.90]$ \\
\hline \multicolumn{4}{|c|}{ Frequency of reading newspaper/magazine } \\
\hline Not at all & & Ref & Ref \\
\hline Less than once a week & & $0.84[0.64-1.09]$ & $0.86[0.66-1.13]$ \\
\hline At least once a week & & $1.44^{*}[1.04-1.99]$ & $1.40^{*}[1.01-1.95]$ \\
\hline \multicolumn{4}{|c|}{ Frequency Watching television } \\
\hline Not at all & & $1.19^{*}[1.02-1.39]$ & $1.13[0.96-1.32]$ \\
\hline Less than once a week & & $1.30^{* *}[1.11-1.54]$ & $1.28^{* *}[1.08-1.51]$ \\
\hline At least once a week & & Ref & Ref \\
\hline \multicolumn{4}{|c|}{ Household and community factors } \\
\hline \multicolumn{4}{|l|}{ Region } \\
\hline Western & & & $1.38^{*}[1.04-1.82]$ \\
\hline Central & & & $1.53^{* *}[1.16-2.02]$ \\
\hline Greater Accra & & & $1.09[0.80-1.48]$ \\
\hline Volta & & & $0.86[0.60-1.22]$ \\
\hline Eastern & & & $1.09[0.82-1.46]$ \\
\hline Ashanti & & & Ref \\
\hline Brong Ahafo & & & $1.84^{* * *}[1.40-2.42]$ \\
\hline Northern & & & $2.40^{* * *}[1.77-3.26]$ \\
\hline Upper east & & & $2.57^{* * *}[1.86-3.56]$ \\
\hline Upper west & & & $1.09[0.78-1.53]$ \\
\hline
\end{tabular}


Table 3 Adjusted Odds Ratio for early initiation of breastfeeding in Ghana (Continued)

\begin{tabular}{clll}
\hline Variable & Model I & Model II & Model III \\
& AOR (95\%Cl) & AOR (95\%Cl) & AOR (95\%Cl) \\
\hline pseudo $R^{2}$ & 0.005 & 0.012 & 0.028 \\
Hosmer-Lemoshow & 8.66 & 397.35 & 1113.91 \\
ROC Area & 0.5466 & 0.5694 & 0.6091 \\
\hline
\end{tabular}

${ }^{*} p<0.05,{ }^{* *} p<0.01,{ }^{* * *} p<0.001$. Ref Reference category, Cl Confidence Interval

Source: 2014 Ghana Demographic and Health Survey

of breastfeeding compared to those of 2-4 birth order, those who were delivered by health professionals, those whose mothers were Christians and Akans, respectively. Conversely, children born to mothers who read newspaper/magazine at least once a week were more likely to go through early initiation of breastfeeding compared to those who never read newspaper/magazine $[\mathrm{AOR}=1.40$, $\mathrm{CI}=1.01-1.95]$. Children born to mothers who watched television less than once a week were more likely to go through early initiation of breastfeeding compared to those who watched television at least once a week $[\mathrm{AOR}=1.40, \mathrm{CI}=1.01-1.95]$. Finally, women from the Northern $[\mathrm{AOR}=2.40, \mathrm{CI}=1.77-3.26]$ and Upper East regions $[\mathrm{AOR}=2.57, \mathrm{CI}=1.86-3.56]$ practiced early initiation of breastfeeding compared to those from the Ashanti region (see Table 3).

\section{Discussion}

In this study, we investigated the determinants of early initiation of breastfeeding among child bearing women in Ghana. More than half $(55.7 \%)$ of the surveyed women initiated breastfeeding within the first 1 hour of delivery. It was also found that birth order, type of assistance during delivery, religion, ethnicity, exposure to newspaper, television, and region are associated with early initiation of breastfeeding. The prevalence of early initiation of breastfeeding places Ghana above some low-and middle-income countries such as Nepal where a recent national survey reported $41.8 \%$ breastfeeding initiation within the first 1 hour of delivery [13]. Meanwhile, higher rates of early breastfeeding initiation have been reported from Ethiopia [1], Namibia [15], and Bangladesh [17]. Ghana falls below the WHO guidelines which recommends that all new-borns should be breastfed within the first 1 hour of birth [2]. Early initiation of breastfeeding can be enhanced if positive societal attitude and political will are marshalled to create enabling environment and support systems that will expedite initiation of breastfeeding within the first 1 hour after childbirth. Regulating the breastmilk substitute industries, initiating and establishing effective monitoring systems of early breastmilk initiation for all deliveries could improve the situation $[18,19]$.

We noted a significant association between the type of delivery assistance and early breastfeeding initiation. Women who were assisted by non-health professionals were less likely to initiate breastfeeding within the first hour of delivery. In Ghana, nearly all health professional assisted deliveries take place in health facilities whilst traditional birth attendants dominate in home deliveries [20]. This suggests that most of the women who were assisted by health professionals and initiated breastfeeding within the first hour of delivery gave birth in health facilities. Our observation echoes argument in literature about how obtaining health professional assistance at delivery enhances early breastfeeding initiation [15]. The finding underscores the established relevance of health professionals in sustaining and improving maternal and new-born health [21]. Maternity healthcare providers need to be constantly motivated and reminded through regular educational programmes, memos and reader-friendly audio-visuals in order for them to routinely educate women about the essence of early breastfeeding initiation [22].

Children of first birth order were less likely to have early breastfeeding initiation than those of 2-4 birth order. This finding is consistent with Ethiopia [23] and Nepal [13] based studies which found high occurrence of early initiation of breastfeeding among children who were born second or later compared with first borns. In the case of Nepal, most first borns were fed with prelacteal feeds (e.g. honey or ghutti) prior to breastfeeding [13]. Prelacteal feeds are alien to the Ghanaian culture but we do not doubt the possibility of its gradual permeation into the Ghanaian market and possible preference by primiparous women. These primiparous women might have not initiated early breastfeeding because of the fear that they might not have sufficient milk secretion to breastfeed as it is their first birth [4].

Women who listened to radio at least once a week were more likely to practice early breastfeeding initiation. However, women who watched television once a week had lower odds of early breastfeeding initiation. The benefit of media exposure to early breastfeeding initiation has been reported [23]. Our finding could imply that pro early breastfeeding initiation programmes/advertisements are channelled through radio than television as the former is common, mobile and easily accessible for all Ghanaians irrespective of wealth status 
or location [24]. The finding suggests that in low-and middle-income countries, utilising easily accessible media avenues could yield greater gains in increasing early breastfeeding initiation rate.

Some variations existed across the administrative regions such that women in Northern and Upper East regions had higher chances of early breastfeeding initiation. Geographically, these two regions share a common boundary and both lie in the northern sector of the country. This could imply possible favourable contextual factors within these parts of the country which are not empirically explored. It is worthy of mention that significant ecological variations exist between the northern and southern Ghana [25]. Variation in early breastfeeding initiation due to contextual factors such as agro-ecological zones has also been noted in Nepal [13]. There could be variation in advocacy and recommendation enforcement strategies utilised by health facilities within these locations $[26,27]$.

\section{Strengths and limitations}

This study is a cross sectional survey thereby limiting causal inference. We admit the possibility of recall bias especially among multiparous women. Yet, its national representativeness and large sample enhance generalisability prospects to other low-and middle-income countries especially in Africa. In addition, we could not include other variables such as maternal nutrition status, cultural taboos, and health system related factors that were not captured in the DHS.

\section{Conclusion}

Early initiation of breastfeeding is relatively low in Ghana in light of the WHO recommendation as not all newborns are breastfed within the first 1 hour of delivery. Children of first birth order, those who were delivered by nonprofessionals, those whose mothers were Traditionalists, and Mole-Dagbanis had lower chances of early breastfeeding initiation. Reading newspaper/ magazine, watching television were the factors that enhanced early breastfeeding initiation. Empowering healthcare providers to be consistent in early breastfeeding initiation advocacy and effective community engagement on the need to embrace and practice this can as well improve the situation. Factors contributing to early breastfeeding initiation in the Northern parts of Ghana can be investigated in order to scale up the protective measures to other parts of the country and other low-and middle-income African countries.

\section{Abbreviations}

AOR: Adjusted Odds Ratio; ANC: Antenatal Care; Cl: Confidence Interval; GDHS: Ghana Demographic and Health Survey; GHS: Ghana Health Service; WHO: World Health Organisation

\section{Acknowledgements}

We express our profound gratitude to MeasureDHS for providing us access to the dataset.

\section{Authors' contributions}

A-AS conceived the study. A-AS and BOA performed the analysis and drafted the methods. EKA performed the discussion of the results. BOA wrote the background and the concluding sections. FB did the results write-up and drafted the abstract. All authors reviewed and approved the final version for submission.

\section{Funding}

No funding was received for this study.

\section{Availability of data and materials}

All analysed data are freely available to the public from the Measure DHS website, thus www.measuredhs.org.

\section{Ethics approval and consent to participate}

Ethical approval for the 2014 GDHS was provided by the Ethics Committee of ORC Macro Inc. and Ghana's Ministry of Health. Written or verbal consent was provided by all participated in the survey. Written informed consent was taken from the parents or guardians of participants under age 16. The authors obtained permission to use the dataset from MEASURE DHS.

\section{Consent for publication}

Not applicable.

\section{Competing interests}

The authors declare that they have no competing interests.

\section{Author details}

${ }^{1}$ Department of Population and Health, University of Cape Coast, Cape Coast, Ghana. ${ }^{2}$ College of Public Health, Medical and Veterinary Sciences, James Cook University, Townsville, Queensland, Australia. ${ }^{3}$ School of Public Health, Faculty of Health, University of Technology Sydney, Sydney, Australia. ${ }^{4}$ Asutifi South District Health Directorate, Hwidiem, Ghana.

Received: 15 January 2020 Accepted: 2 October 2020

Published online: 19 October 2020

\section{References}

1. Belachew A. Timely initiation of breastfeeding and associated factors among mothers of infants age 0-6 months old in Bahir Dar City, northwest, Ethiopia, 2017: a community based cross-sectional study. Int Breastfeed J. 2019;14(1):5

2. WHO. Protecting, promoting and supporting breastfeeding in facilities providing maternity and newborn services: Geneva, 2017. [cited 2019/09/10] Available from http://www.who.int/nutrition/publications/guidelines/ breastfeeding-facilities-maternity-newborn/en/ on $9^{\text {th }}$ September, 2019.

3. World Health Organization (2019). Early initiation of breastfeeding to promote exclusive breastfeeding. Available from https://www.who.int/elena/ titles/early_breastfeeding/en on 3rd October, 2019.

4. Abie BM, Goshu YA. Early initiation of breastfeeding and colostrum feeding among mothers of children aged less than 24 months in Debre Tabor, Northwest Ethiopia: a cross-sectional study. BMC Res Notes. 2019;12(1):65.

5. Mugadza G, Zvinavashe M, Gumbo FZ, Pedersen BS. Early breastfeeding initiation and incidence of neonatal sepsis in Chipinge District Zimbabwe. Int J Contemp Pediatr. 2018:5:1.

6. Berkat S, Sutan R. The effect of early initiation of breastfeeding on neonatal mortality among low birth weight in Aceh Province, Indonesia: an unmatched case control study. Adv Epidemiol. 2014:2014;1-7.

7. Smith ER, Hurt L, Chowdhury R, Sinha B, Fawzi W, Edmond KM, Neovita Study Group. Delayed breastfeeding initiation and infant survival: a systematic review and meta-analysis. PLoS One. 2017;12(7):e0180722.

8. NEOVITA Study Group. Timing of initiation, patterns of breastfeeding, and infant survival: prospective analysis of pooled data from three randomised trials. Lancet Glob Health. 2016:4(4):e266-75.

9. Horii N, Allman J, Martin-Prével Y, Dominique W. Determinants of early initiation of breastfeeding in rural Niger: cross-sectional study of community based child healthcare promotion. Int Breastfeed J. 2017;12:412222. 
10. Issaka Al, Agho KE, Renzaho AM. Prevalence of key breastfeeding indicators in 29 sub-Saharan African countries: a meta-analysis of demographic and health surveys (2010-2015). BMJ Open. 2017;7:e014145.

11. Sharma IK, Byrne A. Early initiation of breastfeeding: asystematic literature review of factors and barriers in South Asia. Int Breastfeed J. 2016;11:17.

12. Ghana Statistical Service (GSS), Ghana Health Service (GHS), and ICF International. Ghana Demographic and Health Survey. Rockville, Maryland, USA: GSS, GHS, and ICF International, 2014; 2015.

13. Bhandari S, Thorne-Lyman AL, Shrestha B, et al. Determinants of infant breastfeeding practices in Nepal: a national study. Int Breastfeed J. 2019;14:1.

14. John JR, Mistry SK, Kebede G, Manohar N, Arora A. Determinants of early initiation of breastfeeding in Ethiopia: a population-based study using the 2016 demographic and health survey data. BMC Pregnancy Childbirth. 2019; 19(1):69.

15. Ndirangu MN, Gatimu SM, Mwiny, HM, Kibiwott DC. Trends and factors associated with early initiation of breastfeeding in Namibia: analysis of the Demographic and Health Surveys 2000-2013. BMC Pregn Childbirth 2018; 18(1):171,1-10

16. Tawiah-Agyemang C, Kirkwood BR, Edmond K, Bazzano A, Hill Z. Early initiation of breast-feeding in Ghana: barriers and facilitators. J Perinatol. 2008;28(S2):S46.

17. Karim F, Billah SM, Chowdhury MAK, et al. Initiation of breastfeeding within one hour of birth and its determinants among normal vaginal deliveries at primary and secondary health facilities in Bangladesh: a case-observation study. PLoS One. 2018;13(8):e0202508.

18. Victora CG, Aluísio JD, Barros AJD, França GVA, et al. Breastfeeding in the 21st century: epidemiology, mechanisms, and lifelong effect. Lancet. 2016; 387:475-90.

19. Rollins NC, et al. Lancet breastfeeding series: why invest, and what it will take to improve breastfeeding practices in less than a generation. Lancet. 2016;387:491-504.

20. Ganle JK. Chasing out traditional birth attendants in Ghana-implications for maternal and newborn health. J Global Health. 2014;4:39-42.

21. WHO. 2018 definition of competent maternal and newborn health professionals providing care during childbirth published today; 2018. Retrieved from https://www.who.int/reproductivehealth/definingcompetent-mnh-professionals/en/ on $17^{\text {th }}$ November, 2019.

22. Barnes M, Cox J, Doyle B, Reed R. Evaluation of a practice-development initiative to improve breastfeeding rates. J Perinat Educ. 2010;19(4):17-23.

23. Ekubay M, Berhe A, Yisma E. Initiation of breastfeeding within one hour of birth among mothers with infants younger than or equal to 6 months of age attending public health institutions in Addis Ababa, Ethiopia. Int Breastfeed J. 2018;13:4.

24. Botchway K. Ghana Media Measurement: Top TV and Radio Stations 2018, GeoPoll; 2019. Retrieved from https://www.geopoll.com/blog/ghana-mediameasurement-top-tv-radio-2018/ on 17 $7^{\text {th }}$ October, 2019.

25. Nkrumah F, Klutse N, Adukpo D, Owusu, et al. Rainfall variability over Ghana: model versus rain gauge observation. Int J Geosci. 2014;5:673-83.

26. Zhang F, Cheng J, Yan S, Wu H, Bai T. Early feeding behaviors and breastfeeding outcomes after cesarean section. Breastfeed Med. 2019;14:5.

27. Munn AC, Newman SD, Mueller M, Phillips SM, Taylor SN. The impact in the United States of the baby-friendly hospital initiative on early infant health and breastfeeding outcomes. Breastfeed Med. 2016;11(5):222-30.

\section{Publisher's Note}

Springer Nature remains neutral with regard to jurisdictional claims in published maps and institutional affiliations.

Ready to submit your research? Choose BMC and benefit from:
- fast, convenient online submission
- thorough peer review by experienced researchers in your field
- rapid publication on acceptance
- support for research data, including large and complex data types
- gold Open Access which fosters wider collaboration and increased citations
- maximum visibility for your research: over 100M website views per year
At BMC, research is always in progress.
Learn more biomedcentral.com/submissions

